\title{
Improved Electrical Properties of Germanium MOS Capacitors With Gate Dielectric Grown in Wet-NO Ambient
}

\author{
J. P. Xu, P. T. Lai, Senior Member, IEEE, C. X. Li, X. Zou, and C. L. Chan
}

\begin{abstract}
Wet-NO oxidation with or without wet $\mathrm{NH}_{3}$ pretreatment is used to grow GeON gate dielectric on Ge substrate. As compared to dry NO oxidation, negligible growth of $\mathrm{GeO}_{x}$ interlayer and, thus, a near-perfect $\mathrm{GeON}$ dielectric can be obtained by the wet-NO oxidation. As a result, MOS capacitors prepared by this method show greatly reduced interface-state and oxide-charge densities and gate-leakage current. This should be attributed to the hydrolyzable property of $\mathrm{GeO}_{x}$ in water-containing atmosphere.
\end{abstract}

Index Terms- $\mathrm{GeO}_{x}$ interlayer, Ge MOS capacitors, GeON, wet-NO oxidation.

\section{INTRODUCTION}

$\mathbf{G}$ ERMANIUM MOSFETs with high- $\kappa$ gate dielectrics $\left(\mathrm{ZrO}_{2}\right.$ [1], $\mathrm{HfO}_{2}$ [2]-[5], and $\mathrm{Al}_{2} \mathrm{O}_{3}$ [5]) have received more and more attention for the future high-speed CMOS technology due to the much higher carrier mobilities of $\mathrm{Ge}$ than Si (two times higher for electrons and four times higher for holes). However, since the deposition of high- $\kappa$ material usually occurs in an oxidizing ambient [6], [7], germanium substrate could be oxidized to form the water-soluble and unstable germanium oxide $\left(\mathrm{GeO}_{x}\right)$ [8], [9]. To overcome this problem, various processes were used to improve the interface quality, including $\mathrm{NH}_{3}$ surface treatment [2]-[5], to form a $\mathrm{GeO}_{x} \mathrm{~N}_{y}$ interlayer, and $\mathrm{Si}$ interlayer technique with several monolayers of $\mathrm{Si}$ grown between the dielectric and the substrate by $\mathrm{SiH}_{4}$ surface annealing [10], [11]. However, nitrogen incorporation in the former method may not be sufficient to fully passivate the dangling bonds on the Ge surface and prevent its oxidation, while the thickness of the Si interlayer in the latter method has to be accurately controlled to prevent parasitic Si channel, thus increasing the processing difficulty. In this letter, a novel process is proposed to fabricate high-quality $\mathrm{GeO}_{x} \mathrm{~N}_{y}$ gate dielectric by oxidizing $\mathrm{Ge}$ in an $\mathrm{NO}$ plus water-vapor atmosphere. As a result, the growth of the $\mathrm{GeO}_{x}$ interlayer is effectively suppressed, and high-quality $\mathrm{GeO}_{x} \mathrm{~N}_{y}$ bulk and $\mathrm{GeO}_{x} \mathrm{~N}_{y} / \mathrm{Ge}$

Manuscript received January 23, 2006; revised March 6, 2006. This work was supported by the National Natural Science Foundation of China (NSFC) under Grant 60576021, and the Research Grants Council (RGC) of Hong Kong Special Administrative Region (HKSAR), China, under Project HKU 7142/05E. The review of this letter was arranged by Editor C.-P. Chang.

J. P. Xu and X. Zou are with the Department of Electronic Science and Technology, Huazhong University of Science and Technology, Wuhan 430074, China.

P. T. Lai, C. X. Li, and C. L. Chan are with the Department of Electrical and Electronic Engineering, University of Hong Kong, Hong Kong (e-mail: laip@eee.hku.hk).

Digital Object Identifier 10.1109/LED.2006.874124
TABLE I

OXIDE CAPACITANCE AND THICKNESS, OXIDE-CHARGE AND INTERFACE-STATE DENSITIES, AND FLATBAND VOLTAGE OF THE SAmples Extracted From $100-\mathrm{KHz}$ HF $C-V$ Curve

\begin{tabular}{|c|c|c|c|c|c|}
\hline Sample & $\begin{array}{c}\mathrm{C}_{\mathrm{ox}} \\
(\mathrm{pF})\end{array}$ & $\begin{array}{c}\mathrm{t}_{\mathrm{ox}} \\
(\mathrm{nm})\end{array}$ & $\begin{array}{c}\mathrm{Q}_{\mathrm{ox}} \\
\left(\mathrm{cm}^{-2}\right)\end{array}$ & $\begin{array}{c}\mathrm{D}_{\text {it }} \text { at midgap } \\
\left(\mathrm{cm}^{-2} \mathrm{eV}^{-1}\right)\end{array}$ & $\begin{array}{c}\mathrm{V}_{\mathrm{fb}} \\
(\mathrm{V})\end{array}$ \\
\hline DNOG & 46.1 & 12.1 & $-1.32 \times 10^{12}$ & $1 \times 10^{12}$ & 0.412 \\
\hline WNOG & 60.6 & 9.2 & $-5.72 \times 10^{11}$ & $6 \times 10^{11}$ & 0.171 \\
\hline WNH3NOG & 65.8 & 8.4 & $-5.55 \times 10^{11}$ & $5 \times 10^{11}$ & 0.158 \\
\hline
\end{tabular}

interface with low oxide charge and interface-state densities and greatly reduced gate-leakage current are obtained. This should be due to the water-soluble property of $\mathrm{GeO}_{x}$ in the wet ambient. For comparison, Ge MOS capacitors are also prepared in dry NO ambient. Obvious differences in electrical properties between the wet and dry NO-oxidized samples can be observed.

\section{EXPERIMENTS}

MOS capacitors were fabricated on (100)-oriented n-type Ge substrate with a doping concentration of $2.65 \times 10^{16} \mathrm{~cm}^{-3}$. The wafers were cleaned using trichloroethylene and acetone followed by cyclic HF (50:1 diluted HF solution) dip with DI water rinsing to remove Ge native oxide [2]. Thermal oxidation at $550{ }^{\circ} \mathrm{C}$ was carried out in dry or wet-NO ambients (denoted as DNOG and WNOG samples, respectively). Another sample (WNH3NOG) was prepared first by wet $\mathrm{NH}_{3}$ pretreatment for $2 \mathrm{~min}$ and then by wet-NO oxidation at $550{ }^{\circ} \mathrm{C}$. For a better evaluation of the performance of the $\mathrm{GeON}$ dielectric and the growth of the $\mathrm{GeO}_{x}$ interlayer, a relatively long oxidation time of $20 \mathrm{~min}$ was used to produce a thicker film $(8.4-12.1 \mathrm{~nm}$, as shown in Table I). Then, the WNOG and WNH3NOG samples received a wet $\mathrm{N}_{2}$ anneal, while the DNOG sample had a dry $\mathrm{N}_{2}$ anneal, all for $5 \mathrm{~min}$ at the same temperature. The wet NO, $\mathrm{NH}_{3}$, and $\mathrm{N}_{2}$ atmospheres were realized by bubbling pure $\mathrm{NO}$, $\mathrm{NH}_{3}$, and $\mathrm{N}_{2}$ gases through deionized water at $95^{\circ} \mathrm{C}$ with a flow rate of $250 \mathrm{ml} / \mathrm{min}$ for $\mathrm{NO}$ and $\mathrm{NH}_{3}$ and $500 \mathrm{ml} / \mathrm{min}$ for $\mathrm{N}_{2}$. Al was thermally evaporated and patterned as the gate electrode of the MOS capacitors with an area of $7.85 \times 10^{-5} \mathrm{~cm}^{2}$. Finally, a thermal anneal was carried out in forming gas $\left(\mathrm{H}_{2} / \mathrm{N}_{2}\right)$ ambient for $20 \mathrm{~min}$ at $300{ }^{\circ} \mathrm{C}$.

High-frequency ( $\mathrm{HF}, 100 \mathrm{kHz}$ and $1 \mathrm{MHz}$ ) capacitancevoltage $(C-V)$ characteristics were measured at room temperature using HP4284A precision LCR meter. Oxide capacitance (hence, oxide thickness), flatband voltage, and oxide-charge 


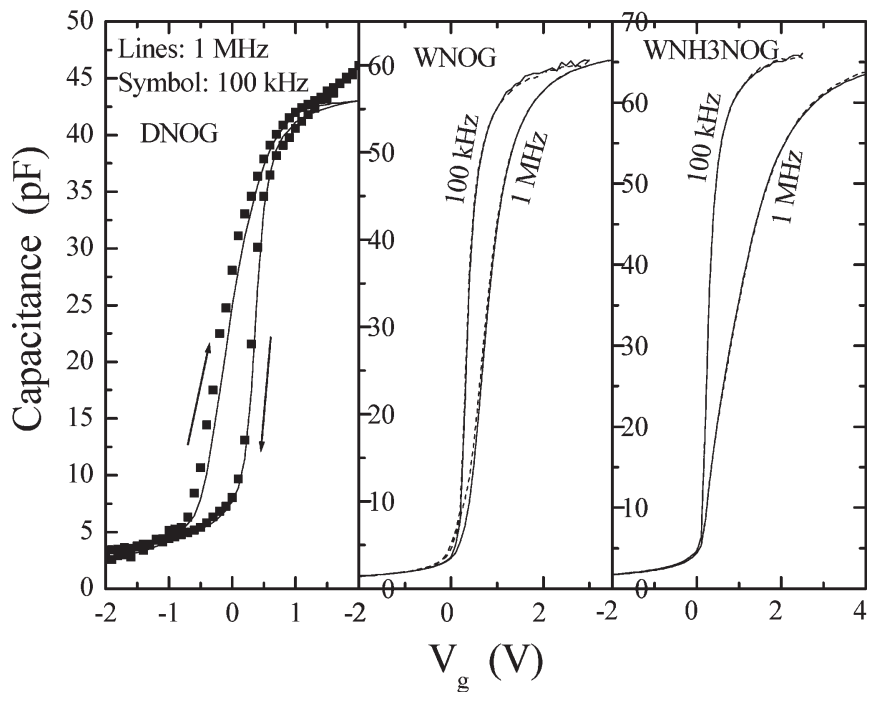

Fig. 1. Typical high-frequency $C-V$ curves of the samples under dark condition at room temperature, swept in both directions at frequencies of $1 \mathrm{MHz}$ and $100 \mathrm{kHz}$, respectively. Area of capacitor is $7.85 \times 10^{-5} \mathrm{~cm}^{2}$. (a) DNOG sample, (b) WNOG sample, and (c) WNH3NOG sample.

density were extracted from the $100-\mathrm{kHz} C-V$ curve. The interface-state density near midgap was extracted also from the $100-\mathrm{kHz} C-V$ curve by the Terman method [12] for the purpose of a relative comparison between different samples. The gateleakage current was measured by HP 4156A precision semiconductor parameter analyzer. All measurements were carried out under a light tight and electrically shielded condition.

\section{RESULTS AND DISCUSSION}

Fig. 1 shows the typical HF $C-V$ curves of the samples under dark condition, swept in both directions and measured at frequencies of $1 \mathrm{MHz}$ and $100 \mathrm{kHz}$, respectively. As expected, a large hysteresis is observed for the DNOG sample due to the growth of the $\mathrm{GeO}_{x}$ interlayer during dry-NO oxidation, leading to high-interface and near-interface trap densities. However, the growth of the $\mathrm{GeO}_{x}$ interlayer gets effectively suppressed when the oxidation is carried out in wet-NO ambient, as shown by the very small hysteresis in the $C-V$ curves of the WNOG and WNH3NOG samples, and their identical $C_{\text {ox }}$ values measured at $1 \mathrm{MHz}$ and $100 \mathrm{kHz}$, which implies less interface and near-interface traps. For comparing the qualities of these oxynitrides and their interface properties with $\mathrm{Ge}$ substrate more clearly, their $C-V$ curves measured at $100 \mathrm{kHz}$ are replotted in Fig. 2. The values of electrical thickness $\left(t_{\mathrm{ox}}\right)$ of the gate oxynitride and flatband voltage $\left(V_{\mathrm{fb}}\right)$ extracted from the $100-\mathrm{kHz} C-V$ curves are listed in Table I, where the flatband voltage $V_{\mathrm{fb}}$ is determined from the flatband capacitance $\left(C_{\mathrm{fb}}\right)$ formula [13] modified by replacing the dielectric constant of $\mathrm{Si}$ with that of $\mathrm{Ge}$

$$
\frac{C_{\mathrm{fb}}}{C_{\mathrm{ox}}}=\left(1+\frac{75.7 \sqrt{T / 300}}{t_{\mathrm{ox}} \sqrt{N}}\right)^{-1}
$$

where $T$ is the temperature in Kelvin, and $N$ is the carrier concentration equal to donor doping as an approximation.

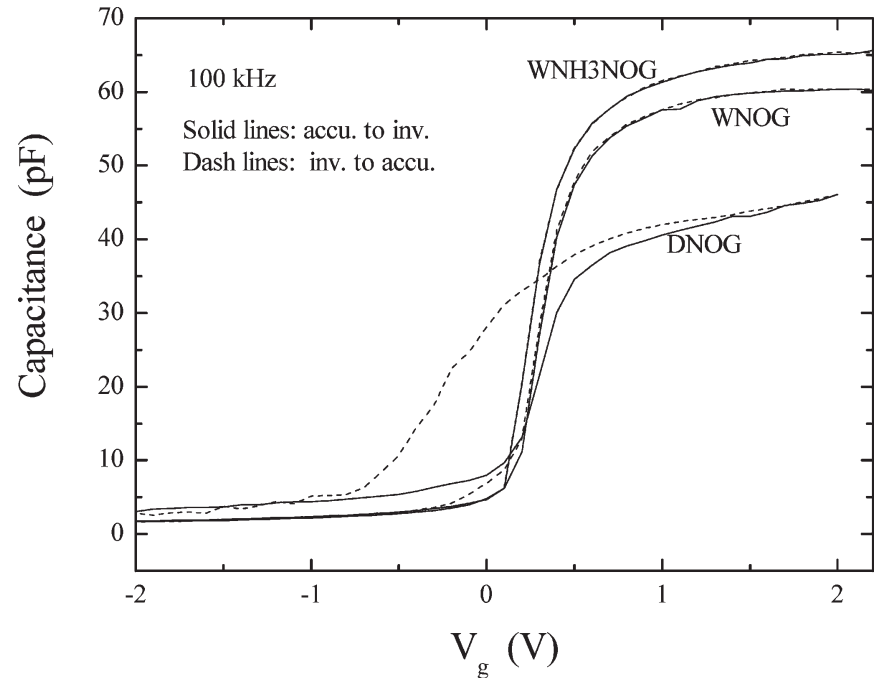

Fig. 2. High-frequency $C-V$ curves of the samples under dark condition at room temperature, swept in both directions at $100 \mathrm{kHz}$. Area of capacitor is $7.85 \times 10^{-5} \mathrm{~cm}^{2}$.

The equivalent oxide-charge density $\left(Q_{\mathrm{ox}}\right)$ is calculated as $-C_{\mathrm{ox}}\left(V_{\mathrm{fb}}-\varphi_{\mathrm{ms}}\right) / \mathrm{q}$, where the work-function difference $\varphi_{\mathrm{ms}}$ between $\mathrm{Al}$ and $\mathrm{Ge}$ is calculated to be $0.053 \mathrm{~V}$. Obviously, the DNOG sample has the smallest $C_{\mathrm{ox}}$, and thus the largest thickness, mainly due to the growth of $\mathrm{GeO}_{x}$ interlayer during dry-NO oxidation. However, the growth of the $\mathrm{GeO}_{x}$ and $\mathrm{GeON}$ with low $\mathrm{N}$ content is considerably suppressed due to their hydrolyzation in the water-vapor atmosphere (i.e., once the $\mathrm{GeO}_{x}$ or $\mathrm{GeON}$ with low $\mathrm{N}$ content is grown, it is hydrolyzed in the wet ambient), thus giving an almost perfect $\mathrm{GeON}$ gate dielectric with smaller thickness and higher $\mathrm{N}$ content for the two samples oxidized in wet-NO ambient. For the WNH3NOG sample, the wet $\mathrm{NH}_{3}$ surface pretreatment prior to the wet-NO oxidation forms a thin nitrogen-terminated passivation layer, which can further prevent the growth of the $\mathrm{GeO}_{x}$ interlayer during the subsequent wet-NO oxidation due to its $\mathrm{O}_{2}$-blocking role, giving a smaller $\mathrm{GeON}$ thickness than that of the WNOG sample. The suppressed growth of $\mathrm{GeO}_{x}$ interlayer in the wetNO ambient is highly desirable for fabricating advanced smallscaled Ge MOSFET with the GeON as gate dielectric or as ultrathin interlayer of high- $\kappa$ stack gate dielectrics. The two wet-NO-oxidized samples exhibit almost identical oxynitride bulk and interface properties with reduced $\mathrm{Q}_{\mathrm{ox}}$ and $D_{\mathrm{it}}$ as compared to the DNOG sample, further supporting the negligible growth of the $\mathrm{GeO}_{x}$ interlayer and thus better interface quality. It should be noted that the WNH3NOG sample seems to have the lowest interface-state density, as shown in Table I, extracted from $100-\mathrm{kHz} C-V$ curves. But its large frequency dispersion in the depletion region and near accumulation indicates a high density of interface states near the bottom of the conduction band. This is probably attributed to the higher nitrogen content in the near-interface $\mathrm{GeON}$ induced by the $\mathrm{NH}_{3}$ pretreatment plus NO oxidation. Therefore, the wet-NO oxidation without $\mathrm{NH}_{3}$ pretreatment should be more beneficial for preparing high-quality thin $\mathrm{GeON}$ as the gate dielectric or interlayer of high- $\kappa$ stack gate dielectric in Ge MOSFET. In addition, the still higher interface-state density of $6 \times 10^{11} \mathrm{~cm}^{-2} \mathrm{eV}^{-1}$ for 


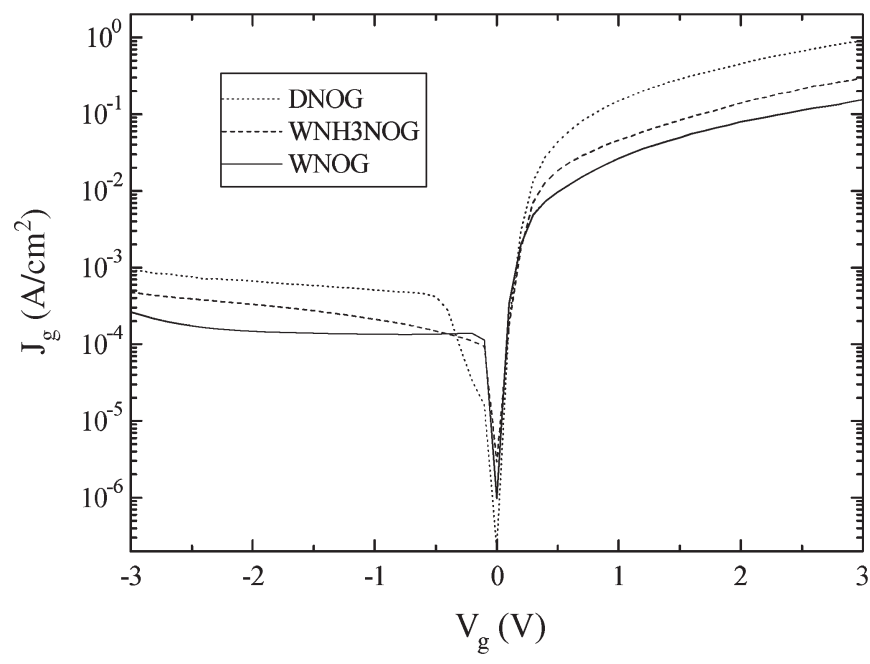

Fig. 3. Gate-leakage properties of the samples.

the WNOG sample (even thou gh it is lower than that of DNOG sample) is speculated to result from the Ge diffusion into $\mathrm{GeON}$ to generate some defects near the interface [14] and possible roughness of the oxynitride/Ge interface. A further study is needed to improve the interface quality.

Fig. 3 shows the gate-leakage properties of the samples. The DNOG sample shows the largest gate-leakage current due to the existence of the $\mathrm{GeO}_{x}$ interlayer. For the two wet-NO-oxidized samples, lower gate-leakage current is observed, despite their smaller $t_{\mathrm{ox}} \mathrm{s}$, than that of the DNOG sample. This should be due to the greatly suppressed $\mathrm{GeO}_{x}$ growth and, thus, low oxidecharge and interface-state densities when the oxidation is performed in the wet-NO ambient, as mentioned above. Slightly larger gate-leakage current of the WNH3NOG sample than that of the WNOG sample is probably associated with the existence of electron traps in the film induced by the $\mathrm{NH}_{3}$ pretreatment [15] as well as its smaller $t_{\mathrm{ox}}$. The negative equivalent oxide charge should be related to the forming-gas anneal and wet oxidation/anneal ambient. The former tends to decrease the positive fixed oxide charge generated by nitridation [16] while the latter could induce negative charges near/at the interface [17]. The origin of the negative charges might be $\mathrm{OH}^{-}$, which cannot diffuse out from the interface at a low temperature of $550{ }^{\circ} \mathrm{C}$ [17]. For the DNOG sample, the negative $Q_{\text {ox }}$ should be mainly due to the high fixed interface-charge and/or nearinterface oxide-trap densities of the $\mathrm{GeO}_{x}$ interlayer because the flatband voltage (thus the equivalent oxide charge) results from the combined effects of fixed oxide charge, mobile ions, and/or near-interface oxide-trap charges near the Fermi level, which respond to the $C-V$ sweeping at room temperature.

\section{SUMmary}

A new wet-NO oxidation with or without wet $\mathrm{NH}_{3}$ surface pretreatment is employed to fabricate $\mathrm{GeON}$ gate dielectric on the Ge substrate. Compared with dry-NO oxidation, the wetNO oxidation followed by a wet $\mathrm{N}_{2}$ anneal gives an almost perfect $\mathrm{GeON}$ gate dielectric with a negligible $\mathrm{GeO}_{x}$ interlayer, greatly reduced interface-state and oxide-charge densities an gate-leakage current. The mechanisms involved probably lie in the hydrolyzable property of $\mathrm{GeO}_{x}$ in water-containing atmosphere. In a word, this technique is highly promising for preparing high-quality $\mathrm{GeON}$ gate dielectric in Ge MOS devices. Moreover, it can easily make excellent ultrathin $\mathrm{GeON}$ interlayer when $\mathrm{HfO}_{2}$ or other high- $\kappa$ dielectrics is used as the gate dielectric of Ge MOSFET.

\section{REFERENCES}

[1] C. O. Chui, H. Kim, D. Chi, B. B. Triplett, P. C. McIntyre, and K. C. Saraswat, "A sub- $400{ }^{\circ} \mathrm{C}$ germanium MOSFET technology with high- $\kappa$ dielectric and metal gate," in IEDM Tech. Dig., 2002, pp. 437-440.

[2] W. P. Bai, N. Lu, J. Liu, A. Ramirez, D. L. Kwong, D. Wristers, A. Ritenour, L. Lee, and D. Antoniadis, "Ge MOS characteristics with $\mathrm{CVD} \mathrm{HfO}_{2}$ gate dielectrics and TaN gate electrode," in VLSI Symp. Tech. Dig., 2003, pp. 121-122.

[3] A. Ritenour, S. Yu, M. L. Lee, N. Lu, W. Bai, A. Pitera, E. A. Fitzgerald, D. L. Kwong, and D. A. Antoniadis, "Epitaxial strained germanium p-MOSFETs with $\mathrm{HfO}_{2}$ gate dielectric and TaN gate electrode," in IEDM Tech. Dig., 2003, pp. 433-436.

[4] C. O. Chui, H. Kim, P. C. Mcintyre, and K. C. Saraswat, "A germanium nMOSFET process integrating metal gate and improved hi- $\kappa$ dielectrics," in IEDM Tech. Dig., 2003, pp. 437-440.

[5] J. J. Chen, N. A. Bojarczuk, H. Shang, M. Copel, J. B. Hannon et al., "Ultrathin $\mathrm{Al}_{2} \mathrm{O}_{3}$ and $\mathrm{HfO}_{2}$ gate dielectrics on surface-nitrided Ge," IEEE Trans. Electron Devices, vol. 51, no. 11, pp. 1441-1447, Nov. 2004.

[6] M. Cho, J. Park, H. B. Park, C. S. Hwang, J. Jeong, and K. S. Hyun, "Chemical interaction between atomic-layer-deposited $\mathrm{HfO}_{2}$ thin films and the Si substrate," Appl. Phys. Lett., vol. 81, no. 2, pp. 334-336, Jul. 2002.

[7] J. Park, B. K. Park, M. Cho, C. S. Hwang, K. Oh, and D. Y. Yang, "Chemical vapor deposition of $\mathrm{HfO}_{2}$ thin films using a novel carbon-free precursor: Characterization of the interface with the silicon substrate," J. Electrochem. Soc., vol. 149, no. 1, pp. G89-G94, Jan. 2002

[8] N. Wu, Q. Zhang, C. Zhu, C. C. Yeo, S. J. Whang et al., "Effect of surface $\mathrm{NH}_{3}$ anneal on the physical and electrical properties of $\mathrm{HfO}_{2}$ films on Ge substrate," Appl. Phys. Lett., vol. 84, no. 19, pp. 3741-3743, May 2004

[9] Y. A. Hu, J.-T. Zettler, S. Chongsawangvirod, Y. Q. Wang, and E. A. Irene, "Spectroscopic ellipsometric measurements of the dielectric function of germanium dioxide films on crystal germanium," Appl. Phys. Lett., vol. 61, no. 9, pp. 1098-1100, Aug. 1992.

[10] W. P. Bai, N. Lu, and D.-L. Kwong, "Si interlayer passivation on germanium MOS capacitors with high- $\kappa$ dielectric and metal gate," IEEE Electron Device Lett., vol. 26, no. 6, pp. 378-380, Jun. 2005.

[11] N. Wu, Q. Zhang, C. Zhu, D. S. H. Chan et al., "A TaN-HfO $2-\mathrm{Ge}$ pMOSFET with novel $\mathrm{SiH}_{4}$ surface passivation," IEEE Electron Device Lett., vol. 25, no. 9, pp. 631-633, Sep. 2004.

[12] L. M. Terman, "An investigation of surface states at a silicon/silicon oxide interface employing metal-oxide-silicon diodes," Solid State Electron., vol. 5, pp. 285-299, 1962.

[13] D. K. Schroder, Semiconductor Material and Device Characterization, 2nd ed. New York: Wiley, 1998.

[14] N. Liu, W. Bai, A. Ramirez et al., "Ge diffusion in Ge metal oxide semiconductor with chemical vapor deposition $\mathrm{HfO}_{2}$ dielectric," Appl. Phys. Lett., vol. 87, p. 51922, Aug. 2005.

[15] T. Hori, H. Iwasaki, Y. Naito, and H. Esaki, "Electrical and physical characteristics of thin nitrided oxides prepared by rapid thermal nitridation," IEEE Trans. Electron Devices, vol. ED-34, no. 11, pp. 2238-2245, Nov. 1987.

[16] C. O. Chui, F. Ito, and K. C. Saraswat, "Scalability and electrical properties of germanium oxynitride MOS dielectrics," IEEE Electron Device Lett., vol. 25, no. 9, pp. 613-615, Sep. 2004.

[17] H. Yano, F. Katafuchi, T. Kimoto et al., "Effects of wet oxidation/anneal on interface properties of thermally oxidized $\mathrm{SiO}_{2} / \mathrm{SiC}$ MOS system and MOSFET's," IEEE Trans. Electron Devices, vol. 46, no. 3, pp. 504-510, Mar. 1999. 